\title{
Dietary intake and processes of behaviour change in a nutrition education intervention for pregnant women in rural Malawi: a cluster-randomised controlled trial
}

\author{
Lillian Ziyenda Katenga-Kaunda ${ }^{1}$, Per Ole Iversen ${ }^{1,2,3, *}$, Gerd Holmboe-Ottesen ${ }^{4}$, \\ Heidi Fjeld ${ }^{4}$, Ibrahimu Mdala ${ }^{4}$ and Penjani Rhoda Kamudoni 1,4,5 \\ 'Department of Nutrition, University of Oslo, PO Box 1046 Blindern, 0316 Oslo, Norway: ${ }^{2}$ Department of \\ Haematology, Oslo University Hospital, Oslo, Norway: ${ }^{3}$ Division of Human Nutrition, Faculty of Global Health, \\ Stellenbosch University, Stellenbosch, South Africa: ${ }^{4}$ Department of Community Medicine and Global Health, \\ University of Oslo, Oslo, Norway: ${ }^{5}$ School of Public Health and Family Medicine, University of Malawi, College of \\ Medicine, Blantyre, Malawi
}

Submitted 25 June 2019: Final revision received 24 December 2019: Accepted 17 January 2020: First published online 18 May 2020

\begin{abstract}
Objective: To examine if increased intake of locally available nutrient-dense foods among pregnant women improved the quality of their dietary intake and if use of the Theory of Planned Behaviour could explain changes in their dietary behaviour. Design: We used data from a randomised controlled trial where the intervention group received nutrition education and dietary counselling. We promoted the use of recipes that utilised powders to enhance dietary diversity. We examined how the intervention achieved changes in dietary intakes and used mixed effects logistic regression models with random effects at village level to explore changes over time of the outcomes, adjusted for selected explanatory variables.

Setting: The study was conducted in twenty villages in rural Malawi.

Participants: Data from 257 pregnant women who were enrolled during late first trimester and followed until birth.

Results: The intervention achieved improvements in the Dietary Diversity Score (DDS) and the Six Food Group Pyramid (SFG) score, especially in intakes of micronutrient-rich foods. A third of the women in the intervention group attained optimal DDS, whereas about $50 \%$ attained optimal SFG. The theorised behaviour mediators (i.e. nutrition attitudes, nutrition behaviour control and subjective norm) that had improved were also significantly associated with high DDS.

Conclusions: Improved dietary intakes were achieved through promoting the use of locally available nutrient-dense foods. Attainment of high DDS was a consequence of the women's belief in the effectiveness of the proposed nutrition recommendations. We identified critical personal and environmental constraints related to dietary intakes during pregnancy in a low-resource setting.
\end{abstract}

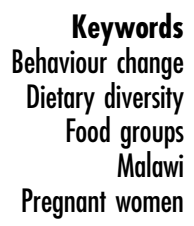

Maternal malnutrition before and during pregnancy accounts for more than half of the low birth weight (LBW, birth weight of $<2500 \mathrm{~g}$ ) infants worldwide ${ }^{(1-3)}$. The prevalence of LBW in sub-Saharan Africa is the second highest in the world $(14 \% \text { in } 2014)^{(3)}$. In Malawi, the prevalence of LBW is about $12 \%$, even so being one of the highest in the region ${ }^{(3,4)}$. LBW is a result of the infant being small for gestational age and/or being born preterm. The consequences of LBW include high infant mortality in the neonatal period and increased risk for later life development of noncommunicable diseases ${ }^{(5-7)}$.
Maternal nutrition is recognised as a modifiable risk factor and an important prerequisite for the attainment of optimal maternal health and neonatal outcomes, for example, by lowering the prevalence of LBW infants ${ }^{(8)}$. This is also the case in Malawi ${ }^{(9)}$, where improving maternal nutrition is one of the seven essential nutrition actions, of which the three main priorities are ${ }^{(10)}$ : (i) community-based action, (ii) promotion of intake of diverse food groups through popularising the Six Food Group Pyramid (SFG) and (iii) multi-mix method of cooking. Although such initiatives exist, intake of foods rich in micronutrients remains a 
challenge among rural Malawian pregnant women ${ }^{(11,12)}$. A typical Malawian meal is made from maize flour, served as a stiff porridge called Nsima and eaten at lunch and dinner. Nsima has a low content of most micronutrients; however, it is supplemented with a relish, made from small dried fish (anchovies) and/or vegetables. Almost $70 \%$ of Malawians come from poor communities ${ }^{(13)}$ where the relish usually comprised of locally accessed vegetables only, whereas well-off communities can afford a relish containing animal sources ${ }^{(14)}$.

Maternal malnutrition has commonly been addressed by nutrition interventions that provide nutrient supplements or fortified foods ${ }^{(15-17)}$ rather than using food-based approaches. Consumption of a more varied diet is associated with improved dietary quality in micronutrients, for example, where animal and dairy products as well as legumes, fruits and vegetables are included ${ }^{(18-20)}$. Foodbased approaches may be the preferred strategy because they are more sustainable, economically feasible and culturally acceptable and can be used to alleviate several micronutrient deficiencies simultaneously, without inducing antagonistic micronutrient interactions ${ }^{(21)}$. However, there are limitations with the effectiveness of food-based interventions, especially when the diets are inadequate in nutrients ${ }^{(18,20)}$, also because most nutrients might be wasted through limited absorption in the gut ${ }^{(20,21)}$. There is thus a need for more sustainable and low-cost community-based nutrition interventions, especially those utilising nutrient-dense foods that are locally produced. We therefore performed a cluster-randomised controlled trial designed to examine if increased intake of locally available nutrient-dense foods among pregnant women in rural Malawi could reduce the prevalence of LBW infants (primary outcome) and increase dietary diversity, pregnancy weight gain and infant birth anthropometry (secondary outcomes).

Here, we specifically report on the nutrition intervention effects on dietary intake of the study participants, as assessed by dietary diversity. We applied concepts from the Theory of Planned Behaviour (TPB) to describe the behavioural, psychosocial factors mediating these effects. The TPB states that the proximal antecedent of a person's behaviour is the 'intention' to perform the recommended behaviour $^{(22)}$. The intention is predicted by three underlying psychosocial cognition-based mechanisms: (i) 'behaviour attitude' - that is, a person's decision-making in relation to the expected behaviour ${ }^{(23-25)}$. Attitude is expressed as 'instrumental' and 'affective'. Instrumental attitude carries an appraisal of the consequences of performing the behaviour, while affective attitude incorporates a self-evaluation of how well a person is inclined towards the expected behaviour; (ii) 'subjective norm' - that is, perceived social pressure to perform or not perform the behaviour; and (iii) 'perceived behaviour control' - that is, behaviour control refers to one's perception of the difficulty or ease of control over the expected behaviour ${ }^{(23,25)}$.

\section{Methods}

\section{Study setting}

We conducted the randomised trial at Namkumba area in Mangochi, Southern Malawi, from January to December 2016. The population of the area is about 150000 , and the inhabitants' occupations are mainly subsistence fishing and/or farming according to their geographical location in relation to Lake Malawi. We report the data according to the CONSORT guidelines.

\section{Selection and recruitment of study participants}

A village was defined as a cluster that did not share a common border with another village eligible to be a cluster. Twenty clusters were mapped out in the study area and were assigned STATA-generated random numbers to allocate them into either the intervention or control group, generating ten clusters per group. We recruited all consenting primi- and multiparous pregnant women between their 9th and 16th gestational week who were available during the study period and planned to give birth at the health facilities within the study area. We excluded women carrying multiple fetuses and those with severe illnesses.

\section{Theoretical framework of the study - Theory of Planned Behaviour}

TPB is useful for understanding food choice, health and dietary behaviour ${ }^{(25,26)}$. TPB was applied to this study to identify the psychosocial processes (behaviour mediators) leading to intervention outcomes both for evaluation purposes and to explain the changes in dietary behaviour. Our intervention aimed at enhancing personal and normative nutrition actions ${ }^{(26)}$ towards sustenance of diverse diets, as a consequence of positive nutrition attitudes and behaviour control. We expected that the use of lay counsellors would enhance the social pressure in the community as well as directly influencing the individual participants' subjective norm. Nutrition education, counselling and cooking demonstrations were the actions designed to influence changes in these behaviour mediators to: (i) enhance individual understanding of the importance of eating diverse food groups; (ii) strengthen the women's motivation to initiate and sustain diversified diets and (iii) facilitate improvement in nutrition-related skills. This theoretical framework has been validated in similar settings ${ }^{(26,27)}$.

\section{Content and delivery of the intervention}

The control group was exposed to the standard antenatal health education given in Malawi. Maternal nutrition is one of the popular topics provided. The nutrition education constitutes summarised information of the recommended food groups to be consumed with no provision of cooking demonstrations. The intervention group was exposed to a more expanded and detailed dietary counselling and education in addition to the one provided through standard 
antenatal care. The specific intervention counselling and education was informed by the findings from a crosssectional pre-study performed among pregnant women in the same study area ${ }^{(12)}$. These findings implied to recommend inclusion of more fats, vitamin C-rich foods and milk in the diet. Through linear programming, we identified possible food combinations which could increase the intakes of most micronutrients ${ }^{(28)}$. The intervention delivery included a monthly nutrition education sessions, followed by cooking demonstrations and weekly individualised counselling sessions.

The intervention promoted consumption of locally produced nutrient-dense food. These foods were not always readily accessible, and many families had to buy them. The most available foods were maize, vegetables, fish and seasonal fruits. Staple taken with only vegetables was the most accessible food combination in the uplands, while in the lakeshore areas, it was staple taken with fish. The most limiting foods were animal foods, some vegetables and legumes ${ }^{(12)}$. The intervention promoted practical ways of addressing challenges relating to food accessibility, that is, the use of food powders of inaccessible foods to optimise dietary diversity of the meals. The recipes utilising these food powders and using multi-mix (one-pot dishes) methods of cooking were developed and promoted. The main ingredients were powders of fish, vegetables and legumes. Use of powders is an effective method of cooking and better suited for the subsistence communities to mitigate inadequate access to food resources, since the ingredients (powders) required less money compared with whole unprocessed foods. Most families could not afford to have Nsima with three different relishes in one meal; however, when powders of fish and ground nuts were used to season vegetables, the diversity of the meal was optimised from two to five food groups (fish as animal food, while ground nuts provided legumes and fats food groups). Furthermore, $100 \mathrm{~g}$ of anchovy was considered enough as relish for one person when taken whole, whereas when used as powder to season vegetables, it was possible to share it among a family. If the powder was used only by the pregnant woman, the $100 \mathrm{~g}$ of anchovy powder could be used for multiple servings. A set of snacks and main meals recipes utilising these food powders were developed and pretested prior to their use in the intervention. We promoted multi-mix (one-pot dishes) methods of cooking where the powders were thoroughly cooked to address hygiene and food safety issues during the processing of the powders.

The intervention also promoted consumption of adequate amounts of food through the following comprehensive dietary recommendations: (i) diverse food groups in the main meals as well as in supplementary meals; (ii) frequent meals and snacks (at least five eating times per day); (iii) double the usual portions of relish (i.e. vegetables, legumes, meats, fish and nuts); (iv) Fe supplements; (v) fruits; (vi) vitamin-C-rich fruit following a meal with beans and (vii) $50 \mathrm{ml}$ of milk (fresh goat milk or from cow milk powder) at least twice a week.

It was not possible to use measurements for portioning out foods since this would be perceived as cumbersome to the participants. However, if complying with this comprehensive dietary plan, it could serve as a proxy for adequate consumption. The intervention also promoted absorption of these micronutrients through use of partially fermented whole grains and soaking beans overnight before cooking to reduce the concentration of phytate and polyphenols that inhibit absorption of Fe, $\mathrm{Zn}$ and $\mathrm{Ca}$ and the use of oils with green leafy vegetables and fruits to promote absorption of vitamins ${ }^{(20,29)}$.

\section{Measurements of socio-demographic characteristics}

Socio-demographics data included area of residence, age, education level, maternal income (has income/no income), number of previous births, number of people in the household, gender of the household head, food security status the previous year (number of months with experienced food shortage) and socio-economic status using a household asset index based on eleven household items according to their monetary value and given scores (very poor $=$ score $\leq 1.25 ;$ poor $=$ score $1.25-3.75 ;$ well-off $=$ score $>3.75)^{(30)}$.

\section{Assessment of dietary intake}

We used the dietary diversity score (DDS) and the Malawian six food groups (SFG) score to evaluate meal diversity. DDS is the international recommendation for assessing dietary quality in micronutrients ${ }^{(31)}$, while SFG is an example of a food group diversity index that is used to assess dietary quality, including energy ${ }^{(32)}$. The DDS was based on ten food groups as proposed by $\mathrm{FAO}^{(30)}$ : grains, nuts/seeds, dairy, meat/poultry/fish, eggs, dark green leafy vegetables, other vegetables, vitamin A-rich fruits, other fruits and legumes/pulses. The Malawian SFG pyramid guide includes six food groups: staple, vegetables, ani$\mathrm{mal} /$ fish food, legumes, fruits and fats. We estimated the DDS from $24 \mathrm{~h}$ dietary recall data collected at baseline and at study end point. This decision was informed by results from our pre-study which showed that there was a significant correlation between DDS and mean nutrition adequacy ratio for eleven micronutrients, whether using either three or only one $24 \mathrm{~h}_{\text {recalls }}{ }^{(12)}$. Each food group was weighted equally with the score of 1 ; hence, the maximum possible score was 10 . The DDS was rated as either poor (score $0-4$ ), moderate (score 5-7) or high (score $\geq 8$ ). The SFG-24 h score was obtained from the $24 \mathrm{~h}$ recall data. Each food group was weighed equally with the score of 1 . The total scores were rated as either poor (score 1-3), moderate (score 4-5) or high (score 6). 


\section{Assessments of behaviour mediators}

The affective attitudes were assessed as women's selfevaluation at baseline and at study end point, that is, before and after the intervention (at delivery) using the same questions: (i) the women were asked if they had changed their diet when they knew they were pregnant, choosing among the answer categories of "eating a diverse diet "less"/"same"/ "more" frequent or being "anorectic". The responses were then collapsed into 'more' if they consumed a diverse diet more frequently and 'less' if they consumed a diverse diet less frequently; (ii) on food choices, the women were asked if they had any consideration before they chose what to eat, their answer alternatives were eating 'anything available'/ 'having nutritional value'/'to satisfy my hunger'/'whatever I desired'/"no consideration'/'other answers'. The responses were collapsed to 'nutritious foods' if they preferred eating nutritious foods and 'no' if they had other answers; and (iii) on use of nutrition advice concerning cooking and eating, the women were asked if they practiced the advice given. Those who said yes were further asked if they practiced the advice 'consistently' or 'occasionally' or 'did not apply them'. The perceived difficulty was measured through assessment of nutrition skills. To this end, we assessed the women's nutrition skills in the preparation of a hypothetical meal, assuming they had access to a variety of foods. We assessed the recipe of the meal using the SFG score of six food groups to evaluate their skills, rating the meal as poor (score 1-3), moderate (score 4-5) or high (score 6). To assess behaviour controllability, the women were asked if they experienced challenges with sustaining a diverse diet, those who said yes were further asked how they handled the situation and their responses were categorised as 'striving' (if the woman was able to sustain a diverse diet with difficulties) and 'managed' (if the woman did not experience challenges with sustaining a diverse diet). Subjective norm was assessed as individual $v$. family involvement in sustaining a diverse diet by asking the woman to evaluate influence of self-initiative over family support on sustenance of the diverse diet, and she was further asked to quantify her contributions or her family contribution towards diet sustenance. The responses were categorised as 'self-initiative' when she was more confident that she was more influential than her family and 'family support' when she indicated very confident that it was due to her family support and also when she was less confident that her contribution was influential.

\section{Statistical analyses}

The trial sample size was 218 and was estimated to be required to detect a difference in mean birth weight of $150 \mathrm{~g}$ between the control and intervention groups, with a power of $80 \%$ and $\alpha=0.05$. Descriptive analysis in SPSS were performed to assess the differences in baseline and study end point characteristics between the two study groups, using the Mann-Whitney $U$ test for continuous variables and the Pearson $\chi^{2}$ test to find associations between categorical variables. We used the mixed effects binary logistic regression models with random effects at village level to explore changes in dietary diversity and the behaviour mediators (constructs of TPB) and differences between the groups from baseline to study end point. Behavioural mediators that were associated with attainment of high DDS were identified in a logistic regression model after adjusting for demographic factors. All models were fitted using Stata se 15, and the significance level was set at $\alpha=0 \cdot 05$. Our choice for mixed effects logistic regression model was based on the fact that our data did not satisfy some of the requirements of a repeated ANOVA, such as equal observations and equal time intervals.

\section{Results}

\section{Characteristics of the study population}

We recruited 257 women and 195 were available for analysis at study end point (Fig. 1).

The average study population were millennials (2237 years old), married, with few children, had attended a few years of primary school and had poor socio-economic status. The women in the intervention group experienced more months of food shortage compared with the controls (Table 1).

\section{Changes in dietary intake of food groups from baseline to study end point}

Increased intakes among the women in the intervention group were observed in the DDS' ten food groups regarding dairy products, dark leafy vegetables, beans/pulses, and nuts and seeds. The SFG-24 h six food groups showed corresponding increases in the consumption of vegetables, legumes and fruits (Table 2).

As shown in Table 3, there was an increase in the percentage attaining high DDS, SFG-24 h and nutrition skills and also in self-initiative, among women in the intervention group at study end point compared with the control group. We also observed an increase in the percentage of women who consumed a diverse diet more frequently, in both study groups. However, there was a decrease in the percentage of women from the intervention group who applied nutrition advice and sustained a diverse diet consistently.

Table 4 shows that most behaviour mediators improved among women in the intervention group at study end point. The odds for attaining high DDS and SFG-24 h were 4.18 and 4.73 times higher, respectively, among women in the intervention group compared with the controls at study end point. Similarly, the odds for eating more diverse foods, attaining optimal nutrition skills and self-initiative, were $3.00,5.96$ and $2 \cdot 89$ times higher, respectively, among women in the intervention group compared with the 


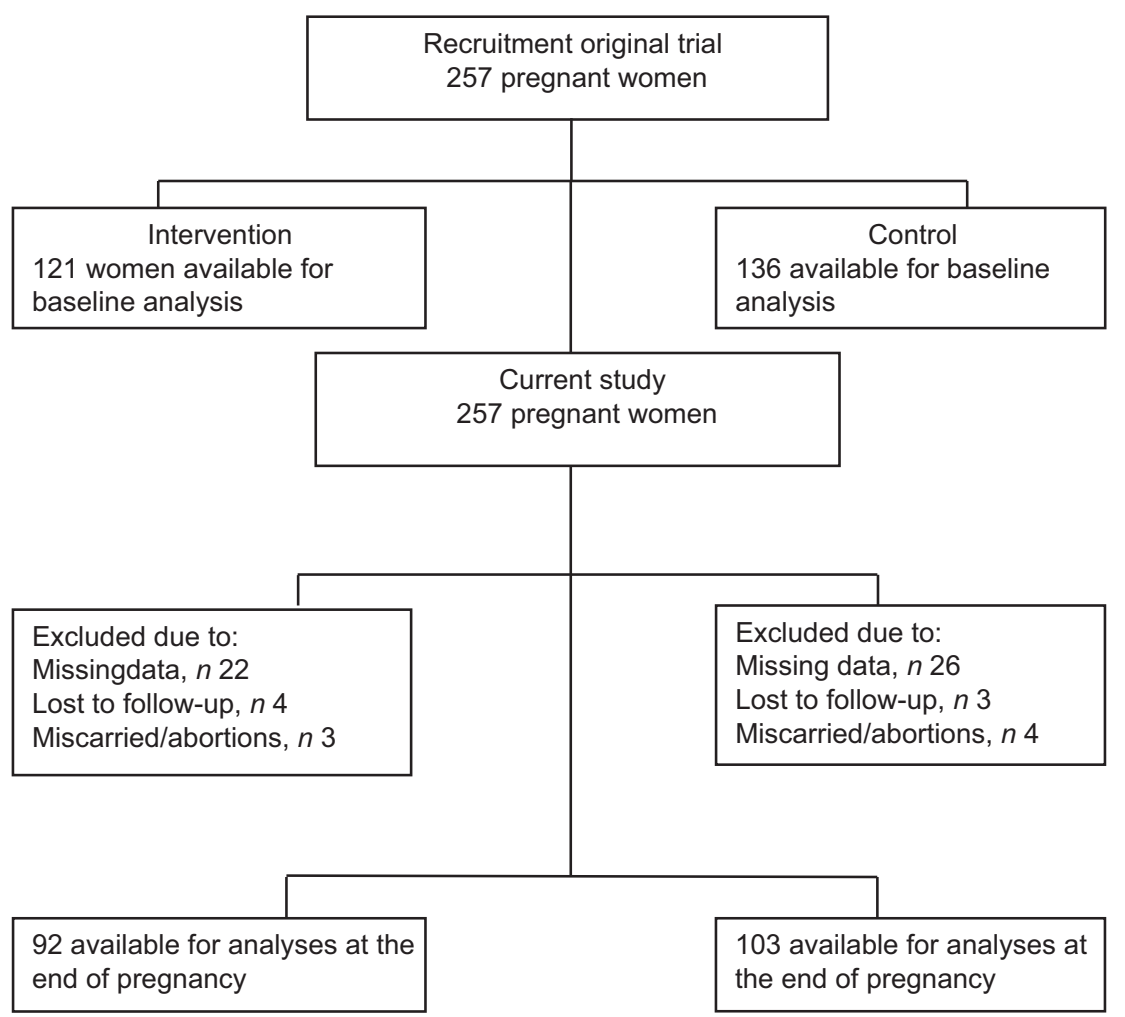

Fig. 1 Flow chart of the inclusion process

Table 1 Baseline characteristics of the study population

\begin{tabular}{|c|c|c|c|c|c|c|c|}
\hline \multirow[b]{2}{*}{ Characteristics } & \multicolumn{3}{|c|}{ Control ( $n$ 103) } & \multicolumn{3}{|c|}{ Intervention ( $n$ 92) } & \multirow[b]{2}{*}{$P$} \\
\hline & $n$ & & $\%$ & $n$ & & $\%$ & \\
\hline \multicolumn{8}{|l|}{ Maternal age (years) } \\
\hline Median & \multirow{2}{*}{\multicolumn{3}{|c|}{$\begin{array}{r}23 \\
18-28\end{array}$}} & \multirow{2}{*}{\multicolumn{3}{|c|}{$\begin{array}{r}24 \\
19-30\end{array}$}} & 0.11 \\
\hline IQR & & & & & & & \\
\hline \multicolumn{8}{|c|}{ Number of previous births } \\
\hline Median & \multirow{2}{*}{\multicolumn{3}{|c|}{$\begin{array}{r}1 \\
0-3\end{array}$}} & \multirow{2}{*}{\multicolumn{3}{|c|}{$\begin{array}{r}2 \\
0-3\end{array}$}} & 0.12 \\
\hline IQR & & & & & & & \\
\hline \multicolumn{8}{|l|}{ Household size } \\
\hline Median & \multirow{2}{*}{\multicolumn{3}{|c|}{$\begin{array}{r}5 \\
3-6\end{array}$}} & \multirow{2}{*}{\multicolumn{3}{|c|}{$\begin{array}{r}5 \\
3-6\end{array}$}} & 0.06 \\
\hline IQR & & & & & & & \\
\hline \multicolumn{8}{|c|}{ Months of houshold food shortage last year } \\
\hline Median & \multirow{2}{*}{\multicolumn{3}{|c|}{$\begin{array}{r}2 \\
1-5\end{array}$}} & \multirow{2}{*}{\multicolumn{3}{|c|}{$\begin{array}{r}3 \\
1-6\end{array}$}} & 0.05 \\
\hline $\begin{array}{c}\text { IQR } \\
\text { Location }\end{array}$ & & & & & & & \\
\hline \multicolumn{8}{|l|}{ Location } \\
\hline Lakeshore & 60 & & 43 & 43 & & $46 \cdot 7$ & 0.11 \\
\hline Uplands & 58.3 & & $41 \cdot 7$ & 49 & & 53.3 & \\
\hline \multicolumn{8}{|l|}{ Socio-economic status } \\
\hline Very poor & 29 & & $28 \cdot 2$ & 31 & & 33.7 & 0.56 \\
\hline Poor & 43 & & $41 \cdot 7$ & 39 & & 42.4 & \\
\hline Well-off & 31 & & $30 \cdot 1$ & 22 & & 23.9 & \\
\hline \multicolumn{8}{|l|}{ Maternal income } \\
\hline No income & 83 & & $80 \cdot 6$ & 75 & & 81.5 & 0.87 \\
\hline Has income & 20 & & $19 \cdot 4$ & 17 & & 18.5 & \\
\hline \multicolumn{8}{|l|}{ Marital status } \\
\hline Single & 12 & & $16 \cdot 5$ & 9 & & $4 \cdot 3$ & 0.67 \\
\hline Married & 91 & & 83.5 & 83 & & $95 \cdot 7$ & \\
\hline \multicolumn{8}{|l|}{ Education } \\
\hline Illiterate/primary & 79 & & $78 \cdot 6$ & 79 & & 83.7 & 0.10 \\
\hline Secondary/above & 24 & & 21.4 & 13 & & $16 \cdot 3$ & \\
\hline \multicolumn{8}{|l|}{ Household head } \\
\hline Female & 9 & & $11 \cdot 7$ & 7 & & 4.3 & 0.77 \\
\hline Male & 94 & & $88 \cdot 3$ & 85 & & $95 \cdot 7$ & \\
\hline
\end{tabular}

IQR, interquartile range. 
Table 2 Dietary intake by food groups at baseline and study end ${ }^{\star}$

\begin{tabular}{|c|c|c|c|c|c|c|}
\hline \multirow[b]{2}{*}{ Tool } & \multicolumn{2}{|c|}{ Baseline (\% yes) } & \multirow[b]{2}{*}{$P$} & \multicolumn{2}{|c|}{ Study end point (\% yes) } & \multirow[b]{2}{*}{$P$} \\
\hline & Control ( $n 78)$ & Intervention (n 68) & & Control ( $n 78)$ & Intervention (n 68) & \\
\hline \multicolumn{7}{|l|}{ DDS food group } \\
\hline Grains/tubers & $100 \cdot 0$ & $100 \cdot 0$ & 1 & $100 \cdot 0$ & $100 \cdot 0$ & 1 \\
\hline Dairy & 9.0 & $11 \cdot 6$ & 0.60 & $12 \cdot 8$ & $22 \cdot 1$ & 0.14 \\
\hline Eggs & $9 \cdot 0$ & $17 \cdot 4$ & 0.13 & $9 \cdot 0$ & $14 \cdot 7$ & 0.28 \\
\hline Meat/poultry/fish & $59 \cdot 0$ & 69.9 & 0.18 & 79.5 & $72 \cdot 1$ & 0.29 \\
\hline Dark leafy vegetables & 59.5 & 56.5 & 0.72 & $48 \cdot 7$ & $72 \cdot 1$ & 0.00 \\
\hline Other vegetables & 81.0 & $91 \cdot 3$ & 0.07 & $91 \cdot 0$ & $97 \cdot 1$ & 0.13 \\
\hline Vitamin A-rich fruits & 63.3 & $61 \cdot 8$ & 0.85 & $57 \cdot 7$ & $69 \cdot 1$ & 0.15 \\
\hline Other fruits & 74.4 & $70 \cdot 6$ & 0.61 & $25 \cdot 6$ & $44 \cdot 1$ & 0.02 \\
\hline Beans/pulses & $32 \cdot 1$ & $26 \cdot 5$ & 0.46 & 29.5 & $44 \cdot 1$ & 0.07 \\
\hline Nuts/seeds & $28 \cdot 2$ & 32.4 & 0.59 & $14 \cdot 1$ & $41 \cdot 2$ & $<0.01$ \\
\hline \multicolumn{7}{|l|}{ SFG-24 $\mathrm{h}$ food group } \\
\hline Staple & $100 \cdot 0$ & $100 \cdot 0$ & 1 & $100 \cdot 0$ & 98.5 & 0.28 \\
\hline Animal food & 66.9 & $75 \cdot 0$ & 0.27 & 84.6 & $76 \cdot 5$ & 0.21 \\
\hline Vegetables & 85.9 & 94.1 & $0 \cdot 10$ & $92 \cdot 3$ & 98.5 & 0.08 \\
\hline Legumes & 41.0 & $45 \cdot 6$ & 0.58 & $33 \cdot 3$ & $69 \cdot 1$ & $<0.01$ \\
\hline Fruits & 78.2 & $70 \cdot 6$ & 0.29 & 73.1 & $85 \cdot 3$ & 0.07 \\
\hline Fats & 67.9 & 73.5 & 0.46 & $71 \cdot 8$ & 80.9 & 0.20 \\
\hline
\end{tabular}

DDS, diet diversity score; SFG-24 $\mathrm{h}$, six food group pyramid $24 \mathrm{~h}$ score.

*Values are the percentage of who ate the food group. $P$-values relate to the differences between the two study groups The $n$ varies due to missing/ incomplete data.

Table 3 Dietary intakes and behaviour mediators at baseline and at study end*

\begin{tabular}{|c|c|c|c|c|c|c|}
\hline \multirow[b]{2}{*}{ Outcomes (\%) } & \multicolumn{3}{|c|}{ Baseline } & \multicolumn{3}{|c|}{ Study end point } \\
\hline & $\begin{array}{c}\text { Control } \\
(n \text { 78-103) }\end{array}$ & $\begin{array}{l}\text { Intervention } \\
\text { (n 68-92) }\end{array}$ & $P$ & $\begin{array}{c}\text { Control } \\
(n \text { 78-103) }\end{array}$ & $\begin{array}{l}\text { Intervention } \\
\text { (n 68-92) }\end{array}$ & $P$ \\
\hline \multicolumn{7}{|l|}{ Dietary intake scores } \\
\hline \multicolumn{7}{|l|}{ DDS } \\
\hline Low (1-4) & $30 \cdot 8$ & 33.8 & \multirow[t]{4}{*}{0.10} & $19 \cdot 2$ & $11 \cdot 8$ & \multirow[t]{4}{*}{$<0.01$} \\
\hline Moderate $(5-7)$ & $64 \cdot 1$ & 51.5 & & 70.5 & $55 \cdot 9$ & \\
\hline High (8-10) & $5 \cdot 1$ & $14 \cdot 7$ & & $10 \cdot 3$ & $32 \cdot 4$ & \\
\hline \multicolumn{5}{|l|}{ SFG } & & \\
\hline Low (1-3) & $32 \cdot 1$ & $30 \cdot 9$ & \multirow[t]{3}{*}{0.32} & $15 \cdot 4$ & $13 \cdot 2$ & \multirow[t]{3}{*}{$<0.01$} \\
\hline Moderate (4-5) & $47 \cdot 4$ & $38 \cdot 2$ & & $66 \cdot 7$ & $36 \cdot 8$ & \\
\hline High (6) & 20.5 & 30.9 & & $17 \cdot 9$ & $50 \cdot 0$ & \\
\hline \multicolumn{7}{|l|}{ Nutrition attitudes } \\
\hline \multicolumn{7}{|c|}{ Intake of diverse food } \\
\hline Less & $79 \cdot 0$ & $68 \cdot 4$ & \multirow[t]{2}{*}{0.13} & $58 \cdot 3$ & $31 \cdot 8$ & \multirow[t]{2}{*}{$<0.01$} \\
\hline More & $21 \cdot 0$ & 31.6 & & 41.7 & 68.2 & \\
\hline \multicolumn{7}{|c|}{ Food choices/preferences } \\
\hline Any food & $75 \cdot 3$ & $71 \cdot 1$ & \multirow[t]{2}{*}{0.55} & 87.5 & $78 \cdot 2$ & \multirow[t]{2}{*}{0.09} \\
\hline Nutritious food & $24 \cdot 7$ & 28.9 & & $12 \cdot 5$ & 21.8 & \\
\hline \multicolumn{7}{|c|}{ Application of nutrition advice } \\
\hline Occasionally & $22 \cdot 2$ & $28 \cdot 2$ & \multirow[t]{2}{*}{0.39} & $32 \cdot 3$ & $67 \cdot 4$ & \multirow[t]{2}{*}{$<0.01$} \\
\hline Consistently & $77 \cdot 8$ & $71 \cdot 8$ & & $67 \cdot 7$ & $32 \cdot 6$ & \\
\hline \multicolumn{7}{|c|}{ Nutrition behaviour control } \\
\hline \multicolumn{7}{|l|}{ Nutrition skills } \\
\hline Poor (1-3) & $27 \cdot 2$ & $29 \cdot 1$ & \multirow[t]{3}{*}{0.95} & $17 \cdot 7$ & $3 \cdot 4$ & \multirow[t]{3}{*}{$<0.01$} \\
\hline Moderate (4-5) & $50 \cdot 6$ & $48 \cdot 1$ & & $58 \cdot 3$ & $51 \cdot 1$ & \\
\hline High (6) & $22 \cdot 2$ & $22 \cdot 8$ & & $24 \cdot 0$ & 45.5 & \\
\hline \multicolumn{7}{|c|}{ Ability to sustain a diverse diet } \\
\hline Strived & 63.7 & $71 \cdot 8$ & \multirow[t]{2}{*}{$0 \cdot 28$} & $68 \cdot 8$ & $80 \cdot 9$ & \multirow[t]{2}{*}{0.06} \\
\hline Managed & $36 \cdot 3$ & $28 \cdot 2$ & & $31 \cdot 2$ & $19 \cdot 1$ & \\
\hline \multicolumn{7}{|l|}{ Subjective norm } \\
\hline \multicolumn{7}{|l|}{ Social support } \\
\hline Herself & $22 \cdot 2$ & $14 \cdot 1$ & 0.19 & $15 \cdot 8$ & 33.7 & 0.01 \\
\hline Family & $77 \cdot 8$ & 85.9 & & $84 \cdot 2$ & $66 \cdot 3$ & \\
\hline
\end{tabular}

DDS, diet diversity score; SFG-24 h, six food group pyramid $24 \mathrm{~h}$ score.

*Values are percentages. The $n$ varies due to missing/incomplete data. 
Table 4 Odds ratios for changes in dietary intakes and behaviour mediators from baseline to study end

\begin{tabular}{|c|c|c|c|c|c|c|c|}
\hline \multirow[b]{2}{*}{ Factor } & \multirow[b]{2}{*}{ Group } & \multicolumn{3}{|c|}{$\begin{array}{l}\Delta \text { within the two study groups } \\
\text { (baseline to study end point) }\end{array}$} & \multicolumn{3}{|c|}{$\begin{array}{l}\text { Difference between the two study } \\
\text { groups (study end point only) }\end{array}$} \\
\hline & & OR & $95 \% \mathrm{Cl}$ & $P$ & OR & $95 \% \mathrm{Cl}$ & $P$ \\
\hline \multicolumn{8}{|l|}{ Dietary intakes } \\
\hline \multirow[t]{2}{*}{ DDS (8-10 food groups) } & Control & $2 \cdot 11$ & $0.61,7.33$ & 0.24 & $4 \cdot 18$ & $1 \cdot 72,10 \cdot 20$ & $<0.01$ \\
\hline & Intervention & $2 \cdot 77$ & $1 \cdot 20,6 \cdot 44$ & 0.02 & & & \\
\hline \multirow[t]{2}{*}{ SFG-24 h (six food groups) } & Control & 0.84 & $0.37,1.87$ & 0.67 & 4.73 & $2 \cdot 05,10.91$ & $<0.01$ \\
\hline & Intervention & $2 \cdot 31$ & $1 \cdot 13,4 \cdot 72$ & 0.02 & & & \\
\hline \multicolumn{8}{|l|}{ Nutrition attitudes } \\
\hline \multirow[t]{2}{*}{ Eating more diverse foods } & Control & $2 \cdot 69$ & $1 \cdot 37,5 \cdot 26$ & 0.00 & 3.00 & $1 \cdot 64,5.49$ & $<0.01$ \\
\hline & Intervention & 4.64 & $2 \cdot 40,8.98$ & $<0.01$ & & & \\
\hline \multirow[t]{2}{*}{ Preference for nutritious foods } & Control & 0.44 & $0.20,0.96$ & 0.04 & 1.96 & $0.89,4.31$ & 0.10 \\
\hline & Intervention & 0.69 & $0.34,1.40$ & 0.30 & & & \\
\hline \multirow[t]{2}{*}{ Consistent use of nutrition advice } & Control & 0.59 & $0.30,1.19$ & 0.14 & 0.26 & $0.11,0.60$ & $<0.00$ \\
\hline & Intervention & 0.17 & $0.09,0.35$ & $<0.01$ & & & \\
\hline \multicolumn{8}{|l|}{ Nutrition behaviour control } \\
\hline \multirow[t]{2}{*}{ Optimal nutrition skills } & Control & $1 \cdot 76$ & $0.85,3.64$ & 0.13 & 5.96 & $1 \cdot 63,21 \cdot 84$ & 0.01 \\
\hline & Intervention & 11.77 & $3 \cdot 36,41 \cdot 22$ & $<0.01$ & & & \\
\hline \multirow[t]{2}{*}{ Diet sustainance striving } & Control & 0.77 & $0.41,1.47$ & 0.43 & 0.55 & $0.25,1 \cdot 20$ & 0.13 \\
\hline & Intervention & 0.59 & $0.28,1.23$ & 0.16 & & & \\
\hline \multicolumn{8}{|l|}{ Subjective norm } \\
\hline \multirow[t]{2}{*}{ Self-initiative } & Control & $0 \cdot 60$ & $0.27,1.33$ & $0 \cdot 21$ & $2 \cdot 89$ & $0.95,8.77$ & 0.06 \\
\hline & Intervention & $3 \cdot 76$ & $1 \cdot 62,8 \cdot 71$ & $<0.01$ & & & \\
\hline
\end{tabular}

$\Delta$, change from baseline to study end point; DDS, diet diversity score; SFG-24 $\mathrm{h}$, six food group pyramid $24 \mathrm{~h}$ score.

controls. However, the women in the intervention group experienced challenges with the consistence in applying nutrition advice; the odds for applying nutrition advice were lower among the women in the intervention group compared with the controls (Table 4).

\section{Determinants for the improved dietary intakes}

As shown in Fig. 2, both univariate and multivariate analysis yielded higher odds for attaining high DDS among the women in the intervention group and those who expressed that they consumed diversified diet more frequently and improved in self-initiative.

\section{Discussion}

We found that the intervention achieved improvements in consumption of micronutrient-rich food groups and resulted in a higher percentage of women achieving the highest categories of the DDS- and SFG-24 h scores. Most of the behavioural mediators improved significantly and they were also significantly associated with the proportion attaining highest dietary diversity. Furthermore, our results identified some limitations in the behaviour prediction capabilities of the TPB. This could imply that the intervention group had comparably more difficulties in following the detailed and complex instructions compared with the standard advice given to the control group. At the same time, the pressure to achieve was probably higher in the intervention group.

Food-based interventions have been recommended over provision of fortified supplements ${ }^{(20)}$, as they are more sustainable and can equally contribute to dietary adequacy in micronutrients without risk of antagonistic interactions ${ }^{(33)}$. Our results indicate a positive trend towards use of foodbased interventions to enhance dietary adequacy in micronutrients. Firstly, a third of women in the intervention group attained high DDS and about $50 \%$ of them achieved a high SFG, implying that they were consuming a more diverse diet constituting 8-10 DDS food groups and all the six foods in the SFG. A DDS score $>5$ is a proxy indicator for minimal micronutrient adequacy when nutrition-dense foods are consumed in substantial amounts $\geq 15 \mathrm{~g} / \mathrm{d})^{(18)}$. Secondly, the recommendations on the women's diet entailed mostly foods being rich sources of micronutrients, such as increasing consumption of fish, dairy products, dark leafy vegetables, beans/pulses, and nuts and seeds. Among the animal foods, meat, dairy, eggs and anchovy are the richest sources of micronutrients. In plant foods, the highest levels of micronutrients are found in seeds/nuts, dark leafy vegetables and vitamin A and C-rich fruits ${ }^{(18)}$.

Our results have also shown that the use of SFG recommendations can equally contribute to dietary adequacy in micronutrients during pregnancy ${ }^{(34)}$. Women who consumed according to the SFG recommendations were also among those with high DDS (DDS score $>8$ ), implying that consumption of a diversified meal constituting SFG recommendations may be indicative of micronutrient adequacy. This is important since the standard Malawian nutrition counselling to pregnant women applies the SFG as a guiding principle and not the DDS. As indicated, the DDS is primarily a guide for micronutrient adequacy, whereas the SFG is more concerned with balancing the micronutrient needs with energy requirements. The DDS as a food guide 


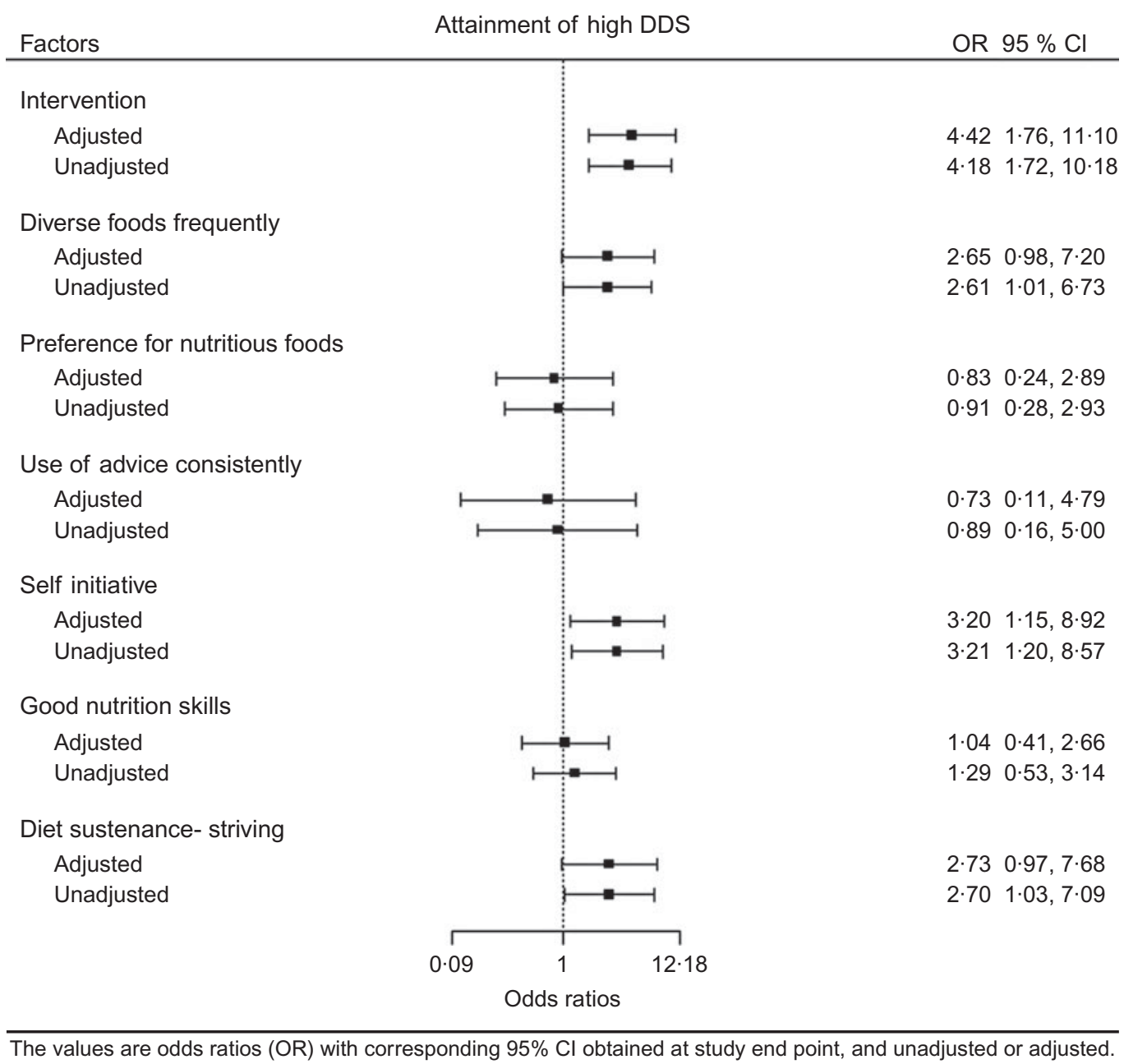

Fig. 2 Univariate and multivariate OR for the determinants for optimal DDS

is, however, more precise for ensuring dietary adequacy in micronutrients than the SFG, since it incorporates most of the nutrition-dense foods. Nevertheless, the SFG is easier to apply in low resource settings.

Our results support the hypothesised effects of the behaviour mediators. As theorised by TPB, behaviour change (improved dietary diversity) would be a consequence of positive nutrition attitudes, perceived nutrition behavioural control and the influence of subjective norm. The central theme in our intervention was to enhance nutrition attitudes through education of health benefits during pregnancy. We aimed to make women recognise the health benefit of sustaining a diverse diet throughout pregnancy, thus outweighing the efforts and resources used in the process. Our results have demonstrated that nutrition attitudes were enhanced whilst also influencing dietary diversity. This implied that the women who indicated that they consumed diverse diets more frequently were more likely to have achieved high DDS. Other studies have reported similar associations ${ }^{(26)}$. Evidence has shown that behaviour change is more evident when the participants are convinced that the expected behaviour has desirable consequences $^{(35)}$. The improved changes in the behaviour mediators and their association with high DDS could indicate the effectiveness of the intervention in instilling positive attitudes, beliefs and expectations of good nutrition during pregnancy.

The women's subjective norm was influenced by the lay counsellors' individualised counselling and by home visits. This led to the enhancement of women's self-initiative in sustaining a diverse diet. The lay counsellors' influence created social pressure in the community as well as influencing the individual participants directly. Exposure to counselling and education services made it possible for the women to strive for better health. Counselling and education have the capacity to change individual attitudes through manipulation of their cognitive processes ${ }^{(26,36)}$ and can equip the women with better understanding of the importance of an adequate diet in pregnancy and help to stimulate continued efforts to sustain a diverse diet ${ }^{(37)}$. These positive attitudes may contribute towards efforts to sustain diverse diets. 
The intervention also promoted the use of powders instead of whole single food items, thus making it easier for the women to sustain diverse diets. If the powders were used in a dish only for the woman, it could be used for more servings. This special adaptation of intervention strategies corresponds to multilevel model of $\mathrm{TPB}^{(35)}$.

As theorised by TPB, nutrition behavioural control is possible when the women have adequate nutrition skills. Cooking demonstrations enhanced nutrition skills which in turn enhanced perceived nutrition behaviour control. However, improvements in nutrition skills were not associated with improvements in DDS. Other studies have related such associations to the limitations of the behaviour prediction capabilities of TPB to external barriers, which are commonly observed when the participants do not have direct volitional control ${ }^{(26,38)}$. The women in the intervention group were unlikely to use their skills and advice if the recommended foods were less accessible, such as in cases of lack of cash or due to seasonal variability in production. Nutrition interventions are successful when counselling and education are integrated with practical services that address food accessibility, that is, through endorsing agricultural production or by economic support ${ }^{(5,20)}$. Furthermore, the nutrition advice and expectations given in the two study groups were not comparable and thus would yield different responses. Unlike the controls, women in the intervention group were subjected to more detailed instructions and thus had to comply with more comprehensive actions; consequently, they experienced challenges in regard to consistent use of the nutrition advice.

Measurements of dietary diversity obtained through DDS lack the quantification of the foods consumed and do not necessarily take into account their entire nutritive profile. Consumption of the required amounts of food would be possible for the women who complied to the recommendation of five servings/d of food that is prepared by the multi-mix method. Moreover, dietary diversity obtained through self-reported data is subjected to error and recall bias. However, self-reporting is commonly used in nutrition assessments and has been shown to have better behaviour prediction capability compared with objective assessments $^{(31,32)}$. The use of the interactive $24-\mathrm{h}$ recall likely enhanced the participant's recall.

In conclusion, the improved dietary intakes were achieved through the use of multi-mix methods of cooking and facilitated by lay counsellors. Our intervention demonstrated that attainment of high DDS was a consequence of the women's belief in the effectiveness of the proposed nutrition recommendations. Positive nutrition attitudes and the behaviour control were important elements in the nutrition education intervention. Furthermore, the use of multi-mix methods of cooking was the main factor that enhanced sustenance of diverse diets. The skills gained are likely to impact dietary intakes also during breast-feeding and subsequent pregnancies.

\section{Acknowledgements}

Acknowledgements: The authors thank the women who participated in this study and their families, the people of Nankumba who welcomed us into their communities and the Malawian health workers and the interviewers involved in this study. Financial support: This project was funded by the University of Oslo, The Global Health and Vaccination Program (GLOBVAC) of the Research Council of Norway and by the Throne Holst Foundation. The funders had no role in the design, analysis or writing of this article. Conflict of interest: None. Autborship: L.Z.K.K. performed the study, collected and analysed the data and drafted the manuscript. P.O.I., G.H.O. and P.R.K. designed and supervised the study, interpreted the data and read all manuscript drafts. H.F. interpreted the data and read all manuscript drafts. I.M. analysed the data and read all manuscript drafts. All authors read and approved the final manuscript. Ethics of human subject participation: This study was conducted according to the guidelines laid down in the Declaration of Helsinki, and all procedures involving research study participants were approved by the Research Ethics Committee in Malawi and from the Regional Committee for Medical and Health Research Ethics in Norway. Consent to participate was through signature or fingerprint. The study was registered with Clinical trials.gov ID: NCT03136393.

\section{References}

1. Ngwira A \& Stanley CC (2015) Determinants of low birth weight in Malawi: Bayesian geo-additive modelling. PLoS One 10, e0130057.

2. Ramakrishnan U, Grant F, Goldenberg T et al. (2012) Effect of women's nutrition before and during early pregnancy on maternal and infant outcomes: a systematic review. Paediatr Perinat Epidemiol 26, 285-301.

3. UNICEF (2014) Low Birthweight: Country, Regional and Global Estimates. https://www.unicef.org/publications/ index_24840.html (accessed June 2019).

4. National Statistical Office (2016) National Statistical Office, Zomba, Malawi: NSO and ICF. https://dhsprogram.com/ publications/publication-fr319-dhs-final-reports.cfm (accessed June 2019).

5. Black RE, Allen LH, Bhutta ZA et al. (2013) Maternal and child nutrition - Authors' reply. Lancet 382, 1551-1552.

6. Black RE, Allen LH, Bhutta ZA et al. (2013) Maternal and child undernutrition and overweight in low-income and middle-income countries. Lancet 382, 427-451.

7. Mumbare SS, Maindarkar G, Darade R et al. (2012) Maternal risk factors associated with term low birth weight neonates: a matched-pair case control study. Indian Pediatr 49, 25-28.

8. Bhutta ZA, Ali S, Cousens S et al. (2008) Alma-Ata: Rebirth and revision 6 interventions to address maternal, newborn, and child survival: what difference can integrated primary health care strategies make? Lancet 372, 972-989.

9. Malawi National Nutrition Policy and Strategic Plan (2007) Natural Resources Library for Malawi, Lilongwe. https:// cepa.rmportal.net/Library/government-publications/Malawi $\% 20$ National\%20Nutrition\%20Policy\%20and\%20Strategic\%20 Plan.pdf/view (accessed June 2019). 
10. Maternal Infant, and Young Child \& Nutrition in Malawi (2011) Community Nutrition Workers. New York: UNICEF. http://iycn.wpengine.netdna-cdn.com/files/IYCN-MalawiCounseling-Cards-Dec-2011.pdf (accessed June 2019).

11. Ramlal RT, Tembo M, King CC et al. (2015) Dietary patterns and maternal anthropometry in HIV-infected, pregnant Malawian women. Nutrients 7, 584-594.

12. Hjertholm KG, Iversen PO, Holmboe-Ottesen G et al. (2018) Maternal dietary intake during pregnancy and its association to birth size in rural Malawi: a cross-sectional study. Matern Child Nutr 14, doi: 10.1111/mcn.12433.

13. World Bank (2018) Malawi Economic Monitor: Girls' Education Key for Malawi's Development. https:// www.worldbank.org/en/country/malawi/publication/malawieconomic-monitor-girls-education-key-for-malawis-development (accessed June 2019).

14. World Food Program (2012) Comprehensive Food Security and Vulnerability Analysis (CFSVA) and Nutrition Assessment. https://www1.wfp.org/publications?fB0D=publica tion_typeA2121\&fB1D=topicsA2122\&fB2D=topicsA2123\& $\mathrm{fB} 3 \mathrm{D}=$ topicsA2130\&text $=\&$ page $=0$ (accessed June 2019).

15. WHO (2013) Global Action Plan. http://africahealthforum. afro.who.int/first-edition/IMG/pdf/global_action_plan_for_ the_prevention_and_control_of_ncds_2013-2020.pdf (accessed June 2019).

16. Bhutta ZA, Das JK, Rizvi A et al. (2013) Evidence-based interventions for improvement of maternal and child nutrition: what can be done and at what cost? Lancet 382, 452-477.

17. Bhutta ZA, Ahmed T, Black RE et al. (2008) What works? Interventions for maternal and child undernutrition and survival. Lancet 371, 417-440.

18. Arimond M, Vitta BS, Martin-Prevel Y et al. (2018) Local foods can meet micronutrient needs for women in urban Burkina Faso, but only if rarely consumed micronutrientdense foods are included in daily diets: a linear programming exercise. Matern Child Nutr 14, 1.

19. Kennedy G, Berardo A, Papavero C et al. (2010) Proxy measures of household food consumption for food security assessment and surveillance: comparison of the household dietary diversity and food consumption scores. Public Health Nutr 13, 2010-2018.

20. Allen LH (2008) To what extent can food-based approaches improve micronutrient status? Asia Pac Clin Nutr 17, Suppl. $1,103-105$.

21. Gibson RS \& Ferguson EL (1998) Nutrition intervention strategies to combat zinc deficiency in developing countries. Nutr Res Rev 11, 115-131.

22. Ajzen I (1991) Theory of planned behaviour. Organ Behav Hum Decis Process 50, 179.

23. Ajzen I (1985) From intentions to actions: a theory of planned behavior. In Action Control: From Cognition to Behavior, pp. 11-39 [J Kuhl \& J Beckman, editors]. Heidelberg: Springer.
24. Michie S, Prestwich A \& de Bruin M (2010) Importance of the nature of comparison conditions for testing theory-based interventions: reply. Health Psychol 29, 468-470.

25. Michie S, Hardeman W, Fanshawe T et al. (2008) Investigating theoretical explanations for behaviour change: the case study of ProActive. Psychol Health 23, 25-39.

26. Armitage CJ \& Conner M (2001) Efficacy of the theory of planned behaviour: a meta-analytic review. BrJ Soc Psychol 40, 471-499.

27. Michie S \& Prestwich A (2010) Are interventions theorybased? Development of a theory coding scheme. Health Psychol 29, 1-8.

28. Darmon N, Ferguson E \& Briend A (2002) Linear and nonlinear programming to optimize the nutrient density of a population's diet: an example based on diets of preschool children in rural Malawi. Am J Clin Nutr 75, 245-253.

29. Gibson RS \& Anderson VP (2009) A review of interventions based on dietary diversification or modification strategies with the potential to enhance intakes of total and absorbable zinc. Food Nutr Bull 30, S108-143.

30. Fink G, Victora CG, Harttgen K et al. (2017) Measuring socioeconomic inequalities with predicted absolute incomes rather than wealth quintiles: A comparative assessment using child stunting data from national surveys. Am J Public Health 107, 550-555.

31. FAO and FHI 360 (2016) Minimum Dietary Diversity for Women. http://www.fao.org/3/a-i5486e.pdf (accessed June 2019).

32. Arimond M (2011) Dietary Diversity as a Measure of the Micronutrient Adequacy of Women's Diets in Resource-Poor Areas: Summary of Results from Five Sites. https://www. fantaproject.org/sites/default/files/resources/WDDP_Summary_ Report_Jul2011.pdf (accessed June 2019).

33. Kennedy G, Fanou-Fogny N, Seghieri C et al. (2010) Food groups associated with a composite measure of probability of adequate intake of 11 micronutrients in the diets of women in urban Mali. J Nutr 140, 2070S-2078S.

34. Allen LH (2012) Global dietary patterns and diets in childhood: implications for health outcomes. Ann Nutr Metab 61, Suppl. 1, 29-37.

35. Contento IR (2008) Nutrition education: linking research, theory, and practice. Asia Pac J Clin Nutr 17, Suppl. 1, 176-179.

36. Barker M \& Swift JA (2009) The application of psychological theory to nutrition behaviour change. Proc Nutr Soc 68, 205-209.

37. Cane J, O'Connor D \& Michie S (2012) Validation of the theoretical domains framework for use in behaviour change and implementation research. Implement Sci 7, 37.

38. Lein NL \& Komro KA (2002) Applying theory of planned behaviour to fruit and vegetable consumption of young adolescents. Am J Health Promot 16, 189. 